\title{
Novelty Dimension Overview in Tourist Satisfaction: GCC Case
}

\author{
Muatasim Al Salmi, Norlena Hasnan \\ School of Technology, Management and Logistics (STML), Universiti Utara Malaysia (UUM), \\ 06010 UUM Sintok, Kedah DarulAman, Malaysia
}

\begin{abstract}
E-government construction requires technical development and implementation solutions from private sector in the country. Both sectors, tourism and government are facing obstacles and challenges generated by the advance and improvement in the use of ICTs by consumers and citizens. Ksenia et al. (2014) illustrated that there are 21 dimensions of tourist satisfaction toward aesthetic judgment and effects in behavioral intention to visit and revisit. This report presents the Novelty dimension's overview from the 21 dimensions to be visited and discussed using a case study of GCC interviews in order to conduct conclusion and recommendations to the GCC nations.
\end{abstract}

Keywords: e-tourism, GCC, e-government, Novelty, tourism management

\section{Introduction}

E-government should establish, promote and enhance the idea of e-tourism as a business to the private sector in order to conduct it in a wide manner to improve the tourism in the country and to improve its contribution to the nation's economy. Since, travel motives are attached with destination attributes. The chosen destination or site for a specific holiday or leisure activity has to meet with the motivational demands and provide satisfactory experiences for the person in order to be successful. However, destinations appeal to tourists for certain reasons, including their scale, uniqueness, service... etc. (Hall, 2005). Whereas, the respective destination attributes combination with travel motives results in a destination"s specific attractiveness and more effect in behavioral intention to visit and this motivations are changing with more experience with travel and ,selfdevelopment $^{\text {ee }}$ and ,nature seekingee increases with travel experience. (Stefan et al., 2011). Tourists usually looking for better cost/value ratios and new applications, activities, nature ... etc. which brings the terms like "new tourist" "new tourism" and "new tourism products" to the new innovative tourism practice (Pirnar et al., 2010).Tourists perceptions are complex, and always influenced by various parameters (Go“ssling et al., 2006; Scott, Jones et al., 2008), while put extra considerations to individual tourists may result in unexpected outcomes. On the other hand, media could shape perceptions with uncontrolled having greater weight in influencing individuals and groups. Indeed, perceptions play a major role in tourist decision-making in destination representing an important stage of information processing that is highly important and essential in influencing the actual traveler's personal negotiation outcome of reported or experienced change (Go"ssling\& Hall, 2006a; Moreno \&Becken, 2009; Nawjin\&Peeters, 2010; Scott et al., 2007; Scott, Jones et al., 2008). However, the global scale tourism simulation models demand are highly simplified and have essential valid limitations, including a wide range of tourist-response related to uncertainties (Bigano, Hamilton, \&Tol, 2006; EugenioMartin \&Camos-Soria, 2010; Go“ssling\& Hall, 2006a, 2006b; Hamilton et al., 2005; Moore, 2010; Weaver, 2011). Whereas, negative perceptions could abrupt changes in travel behavior along with longer-term behavioral modification (Go“ssling\& Hall, 2006; Hall, 2005) and these negative perceptions could also arise out of single simple events and extreme events (Denstadli et al., 2011; Nilsson \&Go"ssling, 2012). Econometric studies have a wide uncertainties range with regard to tourist's behavioral response (Scott et al., 2012). However, there is a lack of available studies in governmental rules and relationship between e-government and e-tourism research through the impact of ICT in assessing long-term behavioral intention changes on tourist awareness, activities, satisfaction and destination choice. It is obvious, however, that reductions in global or regional GDP resulting from several aspects affecting tourism or tourists would reduce consumer discretionary wealth available and kept for tourism and have negative repercussions for future anticipated growth in tourism demand (Hall, 2010a).

\section{Literature Review}

"Novelty and familiarity play an important role in tourists" perceptions, and these have been regarded as contrasting concepts for a long time" (Masaki \& Yuichi, 2012; p10). Generally, novelty is defined as the contrast degree between perceptionsof present and experience of pastwhere it is possible to understand that tourists seek to experience something novel through and by their travel. Indeed, novelty-seeking is the main central travel motivation component that influences tourists ${ }^{\text {ee }}$ decision-making process. Hence, this novelty dimension should be treated as a new experience but not necessarily as new modern knowledge(Masaki \& Yuichi, 2012). There are many types and kinds of novelty-seeking constructslike: thrill, adventure, surprise, and boredom-alleviation and tourists have several motivations and diversity of habits to seek for in their trip. Therefore, novelty-seeking relates to varietyseekingthat is the tendency for tourists to switch away from a normal familiar choice made on the most recent and novelty-seeking has a positive impact on satisfaction (Assaker et al., 2011). Hence,Prayag\& Ryan(2012)discussed that there are a positive relationship between noveltyseeking and behavioral re-visit intention by tourists and hence to increase the satisfaction among tourists (Pike et al., 2010; Jalan Research Center, 2011).Which is considered as a component of destination loyalty. If tourists feel a novelty

\section{Volume 5 Issue 2, February 2016}




\section{International Journal of Science and Research (IJSR) \\ ISSN (Online): 2319-7064 \\ Index Copernicus Value (2013): 6.14 | Impact Factor (2014): 5.611}

sensewhile visiting a destination, they will be satisfied and the destination may be perceived and considered as anattractive place. Thus, this may lead to destination loyalty in the future and mouth marketing recommendation to other tourists. Novelty is the Tourism element that could really make nation's tourism worthwhile (Andrew and William, 2012). Ksenia et al. (2014) counted novelty as a remarkable tourist aesthetic judgment dimension. Thus, these researchers have encouraged the ideas of placecongruency and continuity in aesthetic judgment. From the tourists ${ }^{\text {ee }}$ perspective, it appears that novelty plays an important significant role in aesthetic judgment. Tourists consider novel that is never-before seen aspects of a destination as more beautiful and attractive than familiar landscapes (Ksenia et al., 2014).

Novelty is usually illustrated as a characteristic that is dissipative where it gets used up in the enjoyment act through the habituation process. Since, tourists naturally tend to derive middle or less arousal and become less responsive to anincentive after long exposure with affluence rising levels, the consumer's search for novelty plays an increasingly important aspect in motivating their decision making and destination choose (Masaki and Yuichi, 2012). Stefan et al. (2011) argued that not all motivational factors for travel are the same or equally important, with factors relating to novelty and other dimensions but there is little understanding of how this specific motivational factor of novelty-seeking may be affected by climate change.Denstadli, Jacobsen, and Lohmann (2011) also found empirically that inter-cultural differences specifically in novelty dimension in summer time weather preferences among some tourists who has typical different weather conditions such as rain, storms, sunny and snowthat play a significant role in tourist decision- making and responses to behavioral intention to visit and re-visit and in choosing a destination among others (Hall, 2008a; Hall, 2008b; Nilsson\&Go“ssling, 2012). HoweverMoreno (2010), argued that tourists still want to travel to regions where climatic resources are expected to degradeor to damage.

In the current dynamic economy, fitter novelties become more dominant and important over time through selection and enabling more innovative ideas and activities in order to expand tourism market shares (Randelli, Romei and Tortora, 2014). Hence, nations should take care of novel aspects in cities, beaches, historical regions and rural areas (SanagustínFons et al., 2011).Moreover, because more active members tend to be more attracted and influenced by novel destinations, this information could be furnished to specific destinations that are already heavily marketing to culinary tourists (Andreas, 2012). Tourist"s provision of the findings would help these destinations to put together more targeted, attractive promotions that would lure potential markets and enhance tourism sector in the nation (Liu, Norman Pennington, 2013)

\section{Research Methodology}

The researcher sent questionnaire to 20 males and 20 females who are known as travelers in GCC. They are known as Arab Travelers Group. The survey was distributed directly to the respondents due to their high knowledge in tourism and tourist aspects. 17 males and 10 females responded to the questionnaire. This different maybe due to the GCC countries culture with females since they are less responding to several common surveys. At the end the researcher put a threshold of 10 from each gender in order to start the analysis

\section{Findings and Discussion}

After receiving the required answers to the questionnaire from each gender, the findings found to match the expectation and meeting the literature. Table 1 and Figure 1 Below furnishes all the percentages of respondents from each gender.

Table 1: Findings

\begin{tabular}{|l|l|c|c|c|}
\hline & Gender & Agree & Not Important & Dis Agree \\
\hline \multirow{2}{*}{ N1 } & Male & $94.12 \%$ & $5.88 \%$ & $0.00 \%$ \\
\cline { 2 - 5 } & Female & $90.00 \%$ & $10.00 \%$ & $0.00 \%$ \\
\hline \multirow{2}{*}{ N2 } & Male & $94.12 \%$ & $0.00 \%$ & $5.88 \%$ \\
\cline { 2 - 5 } & Female & $90.00 \%$ & $10.00 \%$ & $0.00 \%$ \\
\hline \multirow{2}{*}{ N3 } & Male & $82.35 \%$ & $11.76 \%$ & $5.88 \%$ \\
\cline { 2 - 5 } & Female & $70.00 \%$ & $30.00 \%$ & $0.00 \%$ \\
\hline
\end{tabular}

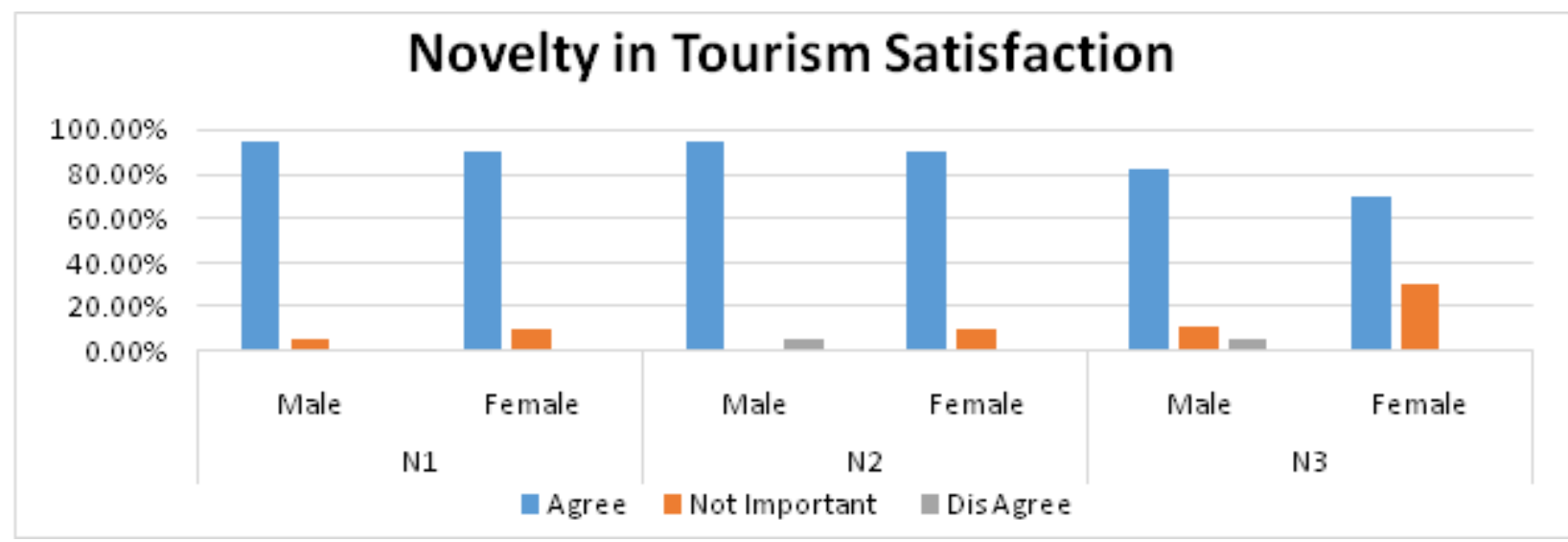

Figure 1: Findings

Three questions about novelty were asked to respondents where two of them found to have obvious and strict answers where respondents from males and females agreed to choose a destination that has nature aspects and views different 


\section{International Journal of Science and Research (IJSR) \\ ISSN (Online): 2319-7064 \\ Index Copernicus Value (2013): 6.14 | Impact Factor (2014): 5.611}

from their original nation in terms of landscapes, weather and views. Almost the same rate received from the second question which was about the life style and the routine of the destination. However, novelty in culture and traditions of the people in the destination found to have some verities in the answers received although still the agreement is considerably high in its effect in decision making procedure especially among male respondents. Most of the respondents gave a common standard comment on novelty questions "if it is not differ from my current routine life, why should I bother to travel to it?", "different weather, style, culture, landscapes activities to get away from the current routine"

\section{Conclusion and Recommendations}

This paper set to review existing studies for developing a major current uncertainties coherent outline and several research needs with regard to tourist responses to novelty dimension in tourist satisfaction. As has been shown, there is an increasing body of literature on the impacts of novelty on tourist behavioral in tension to visit and demand. Thus, tourism sector used in the world to enhance the economic and non-economic benefits for the local community (Kunasekaran et al., 2011). As a result it may be concluded that successful innovation in tourism should bring together important new updated tourism products, service qualities and innovative ideas in tourism industry in an integrated model. When the successful application models of several tourism innovation examples are examined, it becomes obvious that most do have common characteristics among tourists and they share some or all of issues like "sustainability, quality management, cost reduction, etourism, internet usage and / or mobile applications, consumer friendly approaches, CRM, ecology friendly implications, having heritage and culturedimensions, using updated marketing strategies and marketing process" (Pirnar, Bulut and Eris, 2012, p.139). Hence, destinations can seek to deal with adaptation of novelty and lessen potential impacts. Thus, nation should innovate and implement new approaches like: "having a story beyond the product for sale, looking for and applying differential advantage in any way possible" (Pirnar, Bulut and Eris, 2012, p.140). In order to create a competitive advantage, it is recommended for destination marketers to emphasize that their destination offers something novel, new and better to target markets. One way to do this is by developing new and modern tourist attractions or events in the nation. Another way is by giving new meaning and life to the destination by combining culture, history and uniqueness with novelty. Communication strategies must be utilized in order to gain recognition for their efforts like modern communication platforms using social media, e-tourism, e-government and others. On the other hand, combining novelty with familiarity is essential in order to have better combination of attractiveness.

\section{References}

[1] Andrew MacDonald and William Eadington, R., 2012. The Systematic Study of Gaming Operations. UNLV Gaming Research \& Review Journal, 16(2), p.3.

[2] Andreas Chai, 2012, Consumer Specialization and the Demand for Novelty: a Reconsideration of the Links and Implications for Studying Fashion Cycles in Tourism, Griffith University, Germany

[3] Assaker, G., Vinzi, V. E., \& OConnor, P. O. (2011). Examining the effect of novelty seeking, satisfaction, and destination image on tourists ${ }^{\text {ec }}$ return pattern: A two factor, non-linear latent growth model. Tourism Management, $32 \quad$ (4), $\quad 890-901$. http://dx.doi.org/10.1016/j.tourman.2010.08.004

[4] Bigano, A., Hamilton, J. M., \&Tol, R. S. J. (2006). The impact of climate on holiday destination choice. Climatic Change, 76, 389-406.

[5] Denstadli, J., Jacobsen, J., \&Lohmann, M. (2011). Tourist perceptions of summer weather in Scandinavia. Annals of Tourism Research, 38(3), 920-940.

[6] Eugenio-Martin, J. L., \& Campos-Soria, J. A. (2010). Climate in the region of origin and destination choice in outbound tourism demand. Tourism Management, 31, 744-753.

[7] Stefan Go“ssling, Daniel Scott, C. Michael Hall and Jean-Paul Ceron, 2011, CONSUMER BEHAVIOUR AND DEMAND RESPONSE OF TOURISTS TO CLIMATE CHANGE, Pergamon, Sweden

[8] Go“ssling, S., \& Hall, C. M. (2006a). Uncertainties in predicting tourist travel flows based on models. Climatic Change, 79(3-4), 163-173.

[9] Go“ssling, S., \& Hall, C. M. (2006b). Uncertainties in predicting travel flows: common ground and research needs. A reply to Tol et al. Climatic Change, 79(3-4), 181-183.

[10]Hall, C. M. (2005). Tourism: Rethinking the social science of mobility. Harlow: Pearson.

[11]Hall, C. M. (2008a). Tourism and climate change: Knowledge gaps and issues. Tourism Recreation Research, 33, 339-350.

[12] Hall, C. M. (2008b). Santa Claus, place branding and competition. Fennia, 186(1), 59-67.

[13]Hall, C. M. (2010a). Crisis events in tourism: Subjects of crisis in tourism. Current Issues in Tourism, 13, 401417.

[14] Hall, C. M. (2010b). Equal access for all? Regulative mechanisms, inequality and tourism mobility. In S. Cole \& N. Morgan (Eds.), Tourism and inequality: Problems and prospects (pp. 34-48). Wallingford: CABI.

[15] Hamilton, J., Maddison, D., \&Tol, R. S. J. (2005). Climate change and international tourism: A simulation study. Global Environmental Change, 1, 253-266.

[16] IgePirnar, CagriBulut and EnginDeniz Eris, 2012, Improving the performance and competitiveness of tourism establishments by means of innovation: trends and applications, Irat, Turkey

[17] JalanResearch Center. (2011). Jalan travel and accommodation survey 2011 (in Japanese). Retrieved from

http://www.recruit.jp/news_data/data/travel_gourmet/20 110721.pdf

[18] KseniaKirillova, Xiaoxiao Fu, XinranLehto and LipingCai, 2014, What makes a destination beautiful? Dimensions of tourist aesthetic judgment, Elsevier, USA

[19] Kunasekaran, P., Ramachandran, S., Yacob, M. R., \&Shuib, A. (2011). Development of Farmerse Perception Scale on Agro Tourism in Cameron 


\section{International Journal of Science and Research (IJSR) \\ ISSN (Online): 2319-7064}

Index Copernicus Value (2013): 6.14 | Impact Factor (2014): 5.611

Highlands, Malaysia. World Applied Sciences Journal, 12 (T\&H)), 10-18

[20] Liu, I., Norman, W.C. and Pennington-Gray, L., 2013. A Flash of Culinary Tourism: Understanding The Influences of Online Food Photography on People's Travel Planning Process on Flickr. Tourism Culture \& Communication, 13(1), pp.5-18.

[21] Masaki Toyama\& Yuichi Yamada, 2012, The Relationships among Tourist Novelty, Familiarity, Satisfaction, and Destination Loyalty: Beyond the Novelty-familiarity Continuum, IJMS, Japan

[22] Moore, W. (2010). The impact of climate change on Caribbean tourism demand. Current Issues in Tourism, 13, 495-505.

[23] Moreno, A. (2010). Mediterranean tourism and climate (change): A survey-based study. Tourism Planning and Development, 7, 253-265.

[24] Moreno, A., \&Becken, S. (2009). A climate change vulnerability assessment methodology for coastal tourism. Journal of Sustainable Tourism, 17, 473-488.

[25] Nawjin, J., \&Peeters, P. (2010). Travelling ,green ${ }^{\text {ee }}$ is tourists" happiness at stake?. Current Issues in Tourism, 13, 495-505.

[26] Nilsson, J.H. \&Go“ssling, S. (2012). Tourist responses to extreme environmental events: The case of Baltic Sea algal blooms. Tourism Planning and Development, submitted for publication.

[27] Pike, S., Bianchi, C., Kerr, G., \& Patti, C. (2010). Consumer-based brand equity for Australia as a longhaul tourism destination in an emerging market. International Marketing Review, 27(4), 434-449. http://dx.doi.org/10.1108/02651331011058590

[28] Pirnar I., Icoz O. and Icoz O., 2010, The new tourist: impacts on the hospitality marketing strategies, EuroCHRIE Amsterdam: Passion for Hospitality Excellence, 25-28 October 2010, Movenpick Hotel, Amsterdam. Stefan

[29] Prayag, G., \& Ryan, C. (2012). Antecedents of tourists ${ }^{\text {ee }}$ loyalty to Mauritius: The role and influence of destination image, place attachment, personal involvement, and satisfaction. Journal of Travel Research, 51(3), 342-356. http://dx.doi.org/10.1177/0047287511410321

[30] Randelli, F., Romei, P. and Tortora, M., 2014. An evolutionary approach to the study of rural tourism: The case of Tuscany. Land Use Policy, 38, pp.276-281.

[31] SanagustínFons, M.V., Mosene Fierro, J.A., Gómez Patino, M., 2011. Rural tourism: a sustainable alternative. Applied Energy 88, 551-557

[32] Scott, D., Jones, B., \&Konopek, J. (2008). Exploring the impact of climate-induced environmental changes on future visitation to Canadaes Rocky Mountain National Parks. Tourism Review International, 12, 43-56.

[33] Scott, D., Jones, B., \&Konopek, J. (2007). Implications of climate and environmental change for nature-based tourism in the Canadian Rocky Mountains: A case study of Waterton Lakes National Park. Tourism Management, 28, 570-579.

[34] Scott, D., Hall, C. M., \&Go“ssling, S. (2012). Tourism and climate change: Impacts, adaptation and mitigation. London: Routledge.
[35] Selby, M. (2004). Consuming the city: Conceptualizing and researching urban tourist knowledge. Tourism Geographies, 6, 186-207.

[36] Weaver, D. (2011). Can sustainable tourism survive climate change?. Journal of Sustainable Tourism, 19(1), 5-15. 